\title{
Left Atrial Strain by Speckle Tracking Echocardiography not Predicted Functional Capacity in Hypertensive with Normal Systolic Function and Resting Left Atrial Pressure
}

\author{
Gilang Mauladi Rahman, Muhammad Aminuddin, Budi Susetyo Pikir
}

\begin{abstract}
Background: Hypertension is associated with diastolic dysfunction and impaired exercise capacity. Left atrium (LA) has a substantial role to provides an optimal left ventricle diastolic filling. In this study, we aimed to assess the left atrial strain through Speckle Tracking Echocardiography (STE) as a predictor of functional capacity in the hypertensive population.

Methods: A total of 43 hypertensive women (mean age $50 \pm 5.2$ y.o; BMl $28.5 \pm 4.1 \mathrm{Kg} / \mathrm{m} 2$ ) consecutively enrolled in this study. Patients with LVEF $<50 \%$ or significant valvular pathology excluded. Two-dimensional STE performed to asses LA strain parameters, including PALS, PACS, and conduit strain. Functional capacity assessed by treadmill stress test using Bruce protocol.

Results: Mean PALS (Peak Atrial Longitudinal Strain), Peak Atrial Contraction Strain (PACS), and conduit strain in this study was lower than reference normal value $25.8 \%<39 \% ; 12.4 \%<17 \% ; 13.5 \%<23 \%$, respectively). All of the subjects had a preserved systolic function (mean LVEF $72.5 \pm 7.6 \%$ ) and normal resting LA pressure (mean PCWP II $.96 \pm 2.09$ ). Left atrial strain parameters value in the low-fair functional capacity group was not significantly different to average-good functional capacity group $(p>0.05)$. Left atrial strain parameters value was not significantly correlated to exercise duration and achieved METS $(P>0.05)$.

Conclusion: LA strain value in this study was below the standard reference limit. LA strain cannot predict functional capacity in the hypertensive population with preserved ejection fraction and normal resting LA pressure.
\end{abstract}

(Indonesian J Cardiol. 2019;40:319-325)

Keywords: Left, Atrial, Strain, Functional, Hypertensive

Departement of Cardiology and Vascular Medicine, Faculty of Medicine Airlangga University - Pusat Pelayanan Jantung Terpadu DR Soetomo General Hospital, Surabaya, Indonesia

\section{Correspondence:}

Gilang M. Rahman, MD, Departement of Cardiology and Vascular Medicine, Faculty of Medicine Airlangga University - Pusat Pelayanan Jantung Terpadu DR Soetomo General Hospital, Surabaya, Indonesia.

E-mail: gilangmauladirahman@gmail.com

\section{Background}

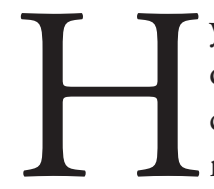

ypertension is one of the most common diseases associated with impaired exercise capacity and heart failure. ${ }^{1}$ Left atrial (LA) remodeling and dysfunction are found to be an independent risk factor for development and progression of heart failure. ${ }^{2}$ LA is not only a simple 
Table. 1 Baseline Demographic And Clinical Data

\begin{tabular}{|c|c|}
\hline Variables & Mean \pm SD, n (\%) \\
\hline $\begin{array}{l}\text { Sex }(n=43) \\
\text { Women }\end{array}$ & $43(100 \%)$ \\
\hline $\begin{array}{l}\text { Age }(\mathrm{y} .0)(\mathrm{n}=43) \\
\cdot \quad 31-40 \\
\cdot \quad 41-50 \\
\cdot \quad 51-60\end{array}$ & $\begin{array}{c}50 \pm 5.1 \\
2(4.7 \%) \\
19(44.2 \%) \\
22(51.1 \%)\end{array}$ \\
\hline $\begin{array}{l}\text { Ethnicity }(n=43) \\
\text { - Javanese }\end{array}$ & $43(100 \%)$ \\
\hline $\begin{array}{l}\text { Body Mass Index / BMI (Kg/m2) (n=43) } \\
\text { - Normal } \\
\text { - Overweight } \\
\text { - Obesity }\end{array}$ & $\begin{array}{l}28.46 \pm 4.14 \\
6(14 \%) \\
25(58.1 \%) \\
12(27.9 \%)\end{array}$ \\
\hline Resting Systolic Blood Pressure (mmHg) & $133.44 \pm 12.15$ \\
\hline Resting Diastolic Blood Pressure (mmHg) & $83.07 \pm 7.83$ \\
\hline $\begin{array}{l}\text { Antihypertensive Medication }(\mathrm{n}=43) \\
\text { - } \text { ACE inhibitors/Angiotensin Receptor Blockers } \\
\text { - } \quad \text { Calcium Channel Blockers } \\
\text { - Beta Blockers } \\
\text { - } \quad \text { Oiuretics } \\
\text { Others }\end{array}$ & $\begin{array}{c}16(37.2 \%) \\
32(74.4 \%) \\
12(27.2 \%) \\
2(4.7 \%) \\
3(7 \%)\end{array}$ \\
\hline Resting Heart Rate & $86.23 \pm 15.30$ \\
\hline Maximum Exercise Duration (Sec.) & $362.14 \pm 99.68$ \\
\hline $\begin{array}{l}\text { Achieved METs } \\
\text { Functional Capacity Categorization }(\mathrm{n}=43) \\
\text { - Low } \\
\text { - } \quad \text { Fair } \\
\text { - } \quad \text { Average } \\
\text { - } \quad \text { Good }\end{array}$ & $\begin{aligned} 9 & (20.9 \%) \\
11 & (25.6 \%) \\
22 & (51.2 \%) \\
1 & (2.3 \%)\end{aligned}$ \\
\hline $\begin{array}{l}\text { Functional Class }(\mathrm{n}=43) \\
\text { - } \quad 1 \\
-\quad 2 \\
-\quad 3\end{array}$ & $\begin{aligned} 26 & (60.5 \%) \\
16 & (37.2 \%) \\
1 & (2.3 \%)\end{aligned}$ \\
\hline
\end{tabular}

passive transport chamber but also highly dynamic and play an essential role to provides an optimal left ventricle diastolic filling. LA have three main functions including the reservoir, conduit, and booster functions. ${ }^{3}$ However, LA function is not studied sufficiently because of measurement difficulties. Standard echocardiography only routinely measures LA structure, but not its physiology. Tissue Doppler imaging has limited accuracy in measuring the LA function, hence restricted in clinical and research settings. ${ }^{4}$

Assessment of strain imaging using Speckle Tracking Echocardiography (STE) makes it possible to measure LA function non-invasively. Strain imaging was feasible and reproducible to measure LA function with high accuracy. More importantly, STE strain imaging technique can detect the impairment of LA function at the very early stage, such as in the absence of LA enlargement. ${ }^{4}$ In the present study, we aimed to assess the LA strain through STE to predicted the functional capacity in the hypertensive population.

\section{Methods}

\section{Study Population}

This study is a cross-sectional observational study including hypertensive women aged 30 - 60 years old between October 2018 to February 2019 in cardiology outpatient clinic, Pusat Pelayanan Jantung Terpadu Dr. Soetomo General Hospital, Surabaya, Indonesia. 
Table. 2 Baseline Echocardiographic Data

\begin{tabular}{|c|c|}
\hline Variables & Mean $\pm S D$, n $(\%)$ \\
\hline $\begin{array}{l}\text { LV Systolic Function } \\
\text { - } \quad \text { LV Ejection Fraction (\%) }\end{array}$ & $72.58 \pm 7.6$ \\
\hline $\begin{array}{ll}\text { LV } & \text { Dimension }(\text { M-Mode }) \\
\text { - } & \text { LVEDD }(\mathrm{cm}) \\
\text { - } & \text { LVESD }(\mathrm{cm}) \\
\text { - } & \text { IVSS }(\mathrm{cm}) \\
\text { - } & \text { IVSD }(\mathrm{cm}) \\
\text { - } & \text { LVPWD }(\mathrm{cm}) \\
\text { - } & \text { LVPWS }(\mathrm{cm}) \\
\text { - } & \text { LVDMI }(\mathrm{g} / \mathrm{m} 2) \\
\text { - } & \text { RWT }\end{array}$ & $\begin{array}{c}4.35 \pm 0.49 \\
3.00 \pm 2.99 \\
1.28 \pm 0.14 \\
0.84 \pm 0.15 \\
1.12 \pm 0.18 \\
1.53 \pm 0.22 \\
87.5 \pm 27.38 \\
0.51 \pm 0.12\end{array}$ \\
\hline $\begin{array}{ll}\text { LV } & \text { Diastolic Function } \\
\text { - } & \text { E Velocity }(\mathrm{m} / \mathrm{s} 2) \\
\text { - } & \text { E/A } \\
\text { - } & \text { Mitral Septal E' }(\mathrm{cm} / \mathrm{s} 2) \\
\text { - } & \text { Mitral Lateral E' }(\mathrm{cm} / \mathrm{s} 2) \\
\text { - } & \text { E/E' } \\
\text { - } & \text { Mitral Septal S' }(\mathrm{cm} / \mathrm{s} 2) \\
\text { - } & \text { LAVI }(\mathrm{mL} / \mathrm{m} 2)\end{array}$ & $\begin{array}{c}0.64 \pm 0.14 \\
0.95 \pm 0.32 \\
8.4 \pm 9.7 \\
9.4 \pm 2.2 \\
9.46 \pm 1.93 \\
6.56 \pm 1.35 \\
24.68 \pm 7.45\end{array}$ \\
\hline $\begin{array}{l}\text { RV Systolic Function } \\
\text { - TAPSE }(\mathrm{cm}) \\
\text { PCWP }(\mathrm{mmHg})\end{array}$ & $\begin{array}{c}2.16 \pm 0.35 \\
11.96 \pm 2.09\end{array}$ \\
\hline $\begin{array}{l}\text { LA Strain Parameters } \\
\text { - } \quad \text { PALS } \\
-\quad \text { PACS } \\
\text { - } \quad \text { Conduit Strain }\end{array}$ & $\begin{array}{c}25.8 \pm 2.95 \\
12.44 \pm 4.44 \\
13.5 \pm 7.54\end{array}$ \\
\hline
\end{tabular}

We excluded subjects with: symptomatic heart failure (NYHA Class III-IV), systolic dysfunction (LVEF $<50 \%$ ), diabetes, significant valvular abnormality and arrhythmia, kidney disease, and physical disability to perform an exercise stress test. Written informed consent obtained from all subjects. Baseline demographic data including age, race, BMI, vital sign and medication history obtained.

\section{Two Dimensional Echocardiography}

Comprehensive transthoracic echocardiography was performed to all subjects using cardiac ultrasound system with digital storage capacity (E), General Electric, Milwaukee, WI, USA). We obtain the basic echocardiographic data using standard two-dimensional echocardiography and tissue Doppler imaging including LA volume, LV dimension, LV systolic and diastolic function, and RV systolic function according to American Society of Echocardiography (ASE) Guidelines5. We estimated the PCWP using Nagueh formula (E velocity/mean mitral E'septal \& E'lateral $* 1.24+1.9){ }^{6}$

\section{Speckle Tracking Echocardiography (STE)}

STE performed using echocardiography software EchoPac $\beta$ (General Electric, Milwaukee, WI, USA). The LA endocardial border from apical four-chamber view with minimal 70 fps was manually defined using a point-and-click technique. An epicardial surface tracing was automatically generated by the system, creating a region of interest, which was manually adjusted to cover the full thickness of the myocardium in the systolic frame. Before processing, a cine loop preview was used to confirm whether the internal line of the region of interest followed the LA endocardial border throughout the cardiac cycle. The software divided the area of interest into six segments and generated the averages of the values and curves of velocity, strain, and strain rate for each segment. The software will reject the suboptimal image and excluded it from the analysis. 
Indonesian Journal of Cardiology

Table. 3 Comparison of LA Strain Parameters Based on Functional Capacity Categorization

\begin{tabular}{lccc}
\hline \multirow{2}{*}{ Variables } & \multicolumn{2}{c}{ Functional Capacity Category (Mean \pm SD) } & \multirow{2}{*}{ p-value } \\
\cline { 2 - 3 } & Low-Fair $(\mathrm{n}=20)$ & Average-Good $(\mathrm{n}=23)$ & \\
\hline LA Strain Parameters & & & $72.58 \pm 7.6$ \\
- PALS (\%) & $25.24 \pm 6.04$ & $26.29 \pm 9.41$ & \\
- PACS (\%) & 22.28 & 21.76 & \\
\hline
\end{tabular}

Statistically significant if the p-value $<0.05$

Table. 4 Correlation of LA Strain Parameters and Maximum Exercise Duration

\begin{tabular}{lcc}
\hline \multicolumn{1}{c}{ LA Strain Parameters } & $\mathrm{r}$ & $\mathrm{p}$-value \\
\hline PALS & 0.08 & 0.58 \\
PACS & 0.00 & 0.98 \\
Conduit Strain & 0.09 & 0.54 \\
\hline
\end{tabular}

Statistically significant if the p-value $<0.05$

Table. 5 Correlation of LA Strain Parameters and Achieved METs

\begin{tabular}{lcc}
\hline \multicolumn{1}{c}{ LA Strain Parameters } & $\mathrm{r}$ & $\mathrm{p}$-value \\
\hline PALS & 0.10 & 0.48 \\
PACS & 0.05 & 0.72 \\
Conduit Strain & 0.08 & 0.58 \\
\hline
\end{tabular}

Statistically significant if the p-value $<0.05$

The LA STE curves were obtained using R-wave onset of the electrocardiogram as a reference point, which enabled the recognition of the first peak, second peak, and the difference of the first and second peaks, each corresponding to LA reservoir/ PALS, contractile/ PACS, and conduit strain, respectively. ${ }^{4}$ Figure 1 shows the curves of LA strain in the STE analysis. ${ }^{7}$

\section{Exercise Stress Test (EST)}

EST performed by treadmill stress test using Bruce protocol, with Borg scale of 14-15. We obtained the baseline hemodynamic data, of achieved age-adjusted METs, and maximum exercise duration of each subject.

\section{Statistical Analysis}

The normality of data distribution examined using Kolmogorov-Smirnov. The correlation between LA strain parameters (PALS, PACS, and Conduit strain) and functional capacity parameters (age-adjusted METs and maximum exercise duration) were analyzed using bivariate analysis with Pearson or Spearman. The mean differences of LA strain parameters in subjects with diastolic dysfunction and normal diastolic function were analyzed using independent- $t$ test or MannWhitney $\mathrm{U}$ test. A $\mathrm{P}$ value $<0.05$ was considered to indicate statistical significance. All statistical analyses were performed using the SPSS ver. 22.0 software (SPSS, Chicago, IL).

\section{Results}

A total of 43 subjects analyzed at the end of the study. All of the subjects were Javanese women with mean aged 50 years old. Subjects were predominantly overweight $(58.1 \%)$ with mean BMI was $28.46 \pm 4.14 \mathrm{~kg} / \mathrm{m}^{2}$. Calcium channel blockers were taken by the majority of the subjects (74.4\%). Mean exercise stress test duration was $362.14 \pm 99.68 \mathrm{sec}$ and mean achieved METs was $18.84 \pm 27.44$. The resting systolic blood pressure, diastolic blood pressure, and heart rate was 133.4 $\pm 12.15 \mathrm{mmHg}, 83.07 \mathrm{mmHg} \pm 7.83 \mathrm{mmHg}$, dan $86.23 \pm 15.13$ beat per minutes respectively. Subjects was predominantly had functional class $1(60.5 \%)$ and "average" functional capacity categorization (51.2\%) (Table.1).

All of the subjects had a preserved LV ejection fraction with mean $\mathrm{EF}$ was $72.58 \pm 7.6 \%$, and normal RV systolic function with mean TAPSE was $2.16 \mathrm{~cm}$. Mean left ventricle end diastolic diameter (LVEDD) was $4.35 \pm 0.49 \mathrm{~cm}$, with mean left ventricle diastolic mass index (LVDMI) and relative wall thickness (RWT) was $87.5 \pm 27.38 \mathrm{~g} / \mathrm{m} 2$ and $0.51 \pm 0.12$ respectively. Mean diastolic function parameters $\mathrm{E}$ velocity was $0.64 \pm$ $0.14 \mathrm{~m} / \mathrm{s}^{2}$, with mean E/A ratio was $0.95 \pm 0.32$. Mean mitral septal E', lateral E', and septal S' were $8.4 \mathrm{~cm} / \mathrm{s}^{2}$, $9.4 \mathrm{~cm} / \mathrm{s}^{2}$, dan $6.5 \mathrm{~cm} / \mathrm{s} 2$ respectively. The mean value of E/E' ratio was $9.46 \pm 1.93$. Subjects predominantly had a mild diastolic dysfunction (72.1\%) with the rest had a normal diastolic function. There were no subjects 
with moderate or severe diastolic dysfunction. All of the subjects had a normal LA volume with mean LAVI was $24.68 \pm 7.45 \mathrm{ml} / \mathrm{m}^{2}$ and normal LA pressure with mean PCWP $11.96 \mathrm{mmHg}$. The mean value of PALS, PACS, and Conduit strain was $25.8 \pm 2.95 \%, 12.44 \pm 4.44 \%$, and $13.5 \pm 7.54$ respectively (Table.2).

There were no significant differences between of PALS, PACS, and conduit strain values in the low-fair functional capacity group and that in the average-good functional capacity group ( $p>0.05$ ) (Table.3). There was no significant correlation between PALS, PACS, and conduit strain values with maximum exercise stress test duration and achieved METs $(\mathrm{p}>0.05)$ (Table.4 \& Table.5).

\section{Discussion}

The value of all LA strain parameters (PALS, PACS, and Conduit strain) in this study was below the standard reference limit based on the previous study. 8,9 This finding was consistent with study from Cameli et al. which revealed that LA strain parameters impaired in hypertensive population with or without diastolic dysfunction. This finding showed that there are LA structural and functional disturbances in hypertensive patients irrespective of the degree of underlying diastolic function. ${ }^{10}$

This study revealed that LAstrain parameters were not significantly different in the low-fair functional capacity group and average-good functional capacity group. LA strain also not correlated well with maximum exercise stress test duration and achieved METs, so it cannot predict the functional capacity in this population. This finding was inconsistent with the previous study which revealed that LA strain parameters were correlated well with functional and exercise capacity. ${ }^{11,12,13}$ However, these studies still involving subjects with a more severe degree of diastolic dysfunction where the LA pressure has increased. This study was only involving subjects with

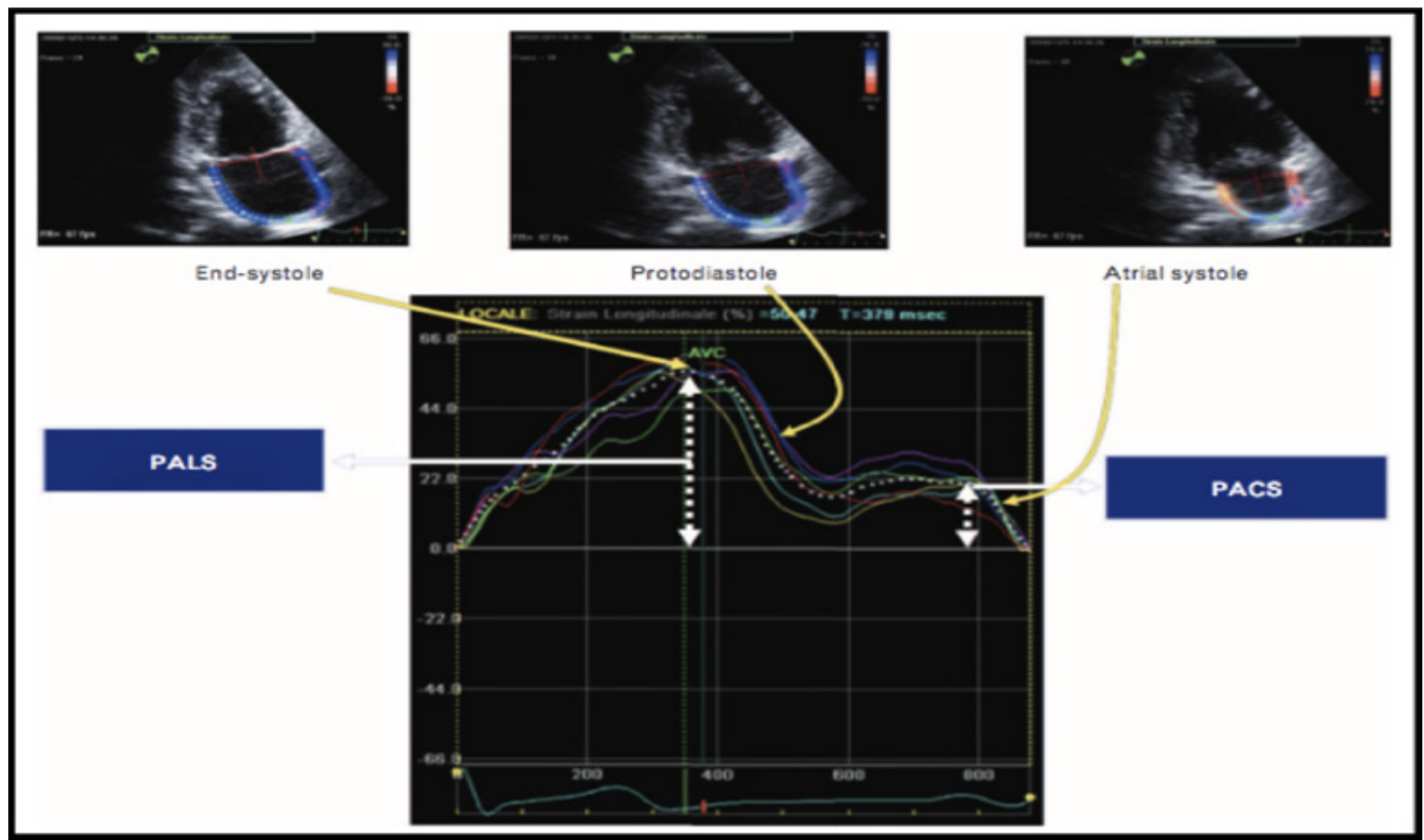

Figure.1 LA Strain Parameters. (Adapted From Cameli M, et al.; Heart Fail Rev. 2016;21:65-76)7

Peak Atrial Longitudinal Strain (PALS): longitudinal strain has increased due to LA filling, and reaches a peak just before the opening of the mitral valve. Peak Atrial Contraction Strain (PACS): The opening of the mitral valve followed by LA emptying leads to a decrease in strains followed by a less positive peak just before atrial contraction. Conduit Strain: PALS - PACS. 
normal diastolic function or mild diastolic dysfunction in which the LA pressure still normal.

\section{Study Limitation}

We examined maximum exercise stress test duration and achieved METs at the maximum exercise which widely used to measure functional capacity, but the achieved maximum oxygen uptake (VO2 max) was unknown because we did not perform the cardiopulmonary exercise test (CPET). We also did not perform the echocardiography during exercise, so the dynamics of LA strain during exercise not precisely known.

\section{Conclusion}

This study revealed that LA strain value was lower than standard reference limit based on the previous study. LA strain cannot predict functional capacity in the hypertensive population when the ejection fraction preserved and LA pressure still normal.

\section{Ethical Clearance}

This study was accepted by ethical committee for medical research of dr Soetomo General Hospital on November $21^{\text {st }}, 2018$, with the certificate number 0806/KEPK/ $\mathrm{XI} / 2018$.

\section{Acknowledgement}

I would like to express my deep gratitude to doctor Muhammad Aminuddin cardiologist and Professor Budi Susetyo Pikir for the advice, enthusiastic support, and significant critiques in this study

\section{Conflict of Interest}

None

\section{Publication Agreement}

The authors of this article permit Indonesian Journal of Cardiology to publish this article if this article is accepted.

\section{Funding}

Self Funded

\section{List of Abbreviations}

LA = Left Atrial

$\mathrm{LV}=$ Left Ventricle

LVEF = Left Ventricle Ejection Fraction

PACS $=$ Peak Atrial Contraction Strain

PALS = Peak Atrial Longitudinal Strain

PCWP= Pulmonary Capillary Wedge Pressure

$\mathrm{RV}=$ Right Ventricle

STE $=$ Speckle Tracking Echocardiography

TAPSE $=$ Tricuspid Annular Plane Systolic Excursion

\section{References}

1. Tadic M, Ivanovic B. Why is functional capacity decreased in hypertensive patients? From mechanisms to clinical studies. J Cardiovasc Med Hagerstown Md. 2014;15:447-455.

2. von Roeder M, Rommel K-P, Kowallick JT, Blazek S, Besler C, Fengler K, Lotz J, Hasenfuß G, Lücke C, Gutberlet M, Schuler G, Schuster A, Lurz P. Influence of Left Atrial Function on Exercise Capacity and Left Ventricular Function in Patients With Heart Failure and Preserved Ejection Fraction. Circ Cardiovasc Imaging. 2017;10.

3. Blume GG, Mcleod CJ, Barnes ME, Seward JB, Pellikka PA, Bastiansen PM, Tsang TSM. Left atrial function: physiology, assessment, and clinical implications. Eur J Echocardiogr. 2011;12:421-430.

4. Xu T-Y, Sun JP, Lee AP-W, Yang XS, Ji L, Zhang Z, Li Y, Yu C-M, Wang J-G. Left Atrial Function as Assessed by Speckle-Tracking Echocardiography in Hypertension. Medicine (Baltimore) [Internet]. 2015 [cited 2017 Oct 26];94. Available from: https:/www.ncbi.nlm.nih.gov/pmc/articles/ PMC4602743/

5. American Society of Echocardiography. American Society of Echocardiography: Guideline Reference Book. 2005.

6. Nagueh SF, Middleton KJ, Kopelen HA, Zoghbi WA, Quiñones MA. Doppler tissue imaging: a noninvasive technique for evaluation of left ventricular relaxation and estimation of filling pressures. $J \mathrm{Am}$ Coll Cardiol. 1997;30:1527-1533.

7. Cameli M, Mandoli GE, Loiacono F, Dini FL, Henein $M$, Mondillo S. Left atrial strain: a new parameter for assessment of left ventricular filling pressure. 
Heart Fail Rev. 2016;21:65-76.

8. Cameli M, Caputo M, Mondillo S, Ballo P, Palmerini E, Lisi M, Marino E, Galderisi M. Feasibility and reference values of left atrial longitudinal strain imaging by two-dimensional speckle tracking. Cardiovasc Ultrasound. 2009;7:6.

9. Pathan F, D'Elia N, Nolan MT, Marwick TH, Negishi K. Normal Ranges of Left Atrial Strain by Speckle-Tracking Echocardiography: A Systematic Review and Meta-Analysis. J Am Soc Echocardiogr Off Publ Am Soc Echocardiogr. 2017;30:59-70.e8.

10. Cameli M, Lisi M, Righini FM, Benincasa S, Solari M, D’Ascenzi F, Focardi M, Lunghetti S, Mondillo S. Left atrial strain in patients with arterial hypertension. Int Cardiovasc Forum J. 2013;1:31-36.

11. Fontes-Carvalho R, Sampaio F, Teixeira M, Ruivo C, Ribeiro J, Azevedo A, Leite-Moreira A, Ribeiro VG. Left atrial deformation analysis by speckle tracking echocardiography to predict exercise capacity after myocardial infarction. Rev Port Cardiol Orgao Of Soc Port Cardiol Port J Cardiol Off J Port Soc Cardiol. 2018;37:821-830.

12. Kusunose K, Motoki H, Popovic ZB, Thomas JD, Klein AL, Marwick TH. Independent association of left atrial function with exercise capacity in patients with preserved ejection fraction. Heart Br Card Soc. 2012;98:1311-1317.

13. D’Andrea A, Caso P, Romano S, Scarafile R, Cuomo S, Salerno G, Riegler L, Limongelli G, Di Salvo G, Romano M, Liccardo B, Iengo R, Ascione L, Del Viscovo L, Calabrò P, Calabrò R. Association between left atrial myocardial function and exercise capacity in patients with either idiopathic or ischemic dilated cardiomyopathy: A two-dimensional speckle strain study. Int J Cardiol. 2009;132:354363. 